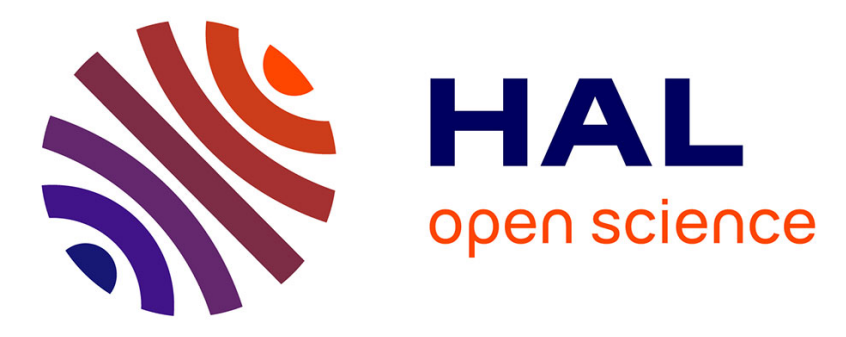

\title{
Use of rifampicin and graft removal are associated with better outcomes in prosthetic vascular graft infection
} Anne Coste, Mélanie Poinot, Sophie Panaget, Bénédicte Albert, Adrien Kaladji, Hervé Le Bars, Nasr Bahaa, Badra Ali, Caroline Piau, Vincent Cattoir, et al.

\section{To cite this version:}

Anne Coste, Mélanie Poinot, Sophie Panaget, Bénédicte Albert, Adrien Kaladji, et al.. Use of rifampicin and graft removal are associated with better outcomes in prosthetic vascular graft infection. Infection, 2021, 49 (1), pp.127-133. 10.1007/s15010-020-01551-z . hal-03101608

\section{HAL Id: hal-03101608 \\ https://hal.science/hal-03101608}

Submitted on 22 Feb 2021

HAL is a multi-disciplinary open access archive for the deposit and dissemination of scientific research documents, whether they are published or not. The documents may come from teaching and research institutions in France or abroad, or from public or private research centers.
L'archive ouverte pluridisciplinaire HAL, est destinée au dépôt et à la diffusion de documents scientifiques de niveau recherche, publiés ou non, émanant des établissements d'enseignement et de recherche français ou étrangers, des laboratoires publics ou privés. 


\section{Title page}

3

$4 \quad$ Intended category: full-length article

5

6 Title: Use of rifampicin and graft removal are associated with better outcomes in prosthetic vascular 7 graft infection

8 Authors: Anne Coste ${ }^{1}$, Mélanie Poinot ${ }^{2}$, Sophie Panaget ${ }^{1}$, Bénédicte Albert ${ }^{3}$, Adrien Kaladji ${ }^{4,5}$, 9 Hervé Le Bars ${ }^{6}$, Nasr Bahaa ${ }^{3}$, Badra Ali ${ }^{3}$, Caroline Piau ${ }^{7}$, Vincent Cattoir ${ }^{7,8}$, Claire de Moreuil ${ }^{1}$, 10 Matthieu Revest ${ }^{2,8,9}$, Rozenn Le Berre ${ }^{1,10}$

\section{Affiliations:}

12 'Service de médecine interne, vasculaire et pneumologie, hôpital la Cavale Blanche, CHRU Brest, 13 France

${ }^{2}$ Infectious Diseases and Intensive Care Unit, CHU Rennes, France

${ }^{3}$ Service de chirurgie cardiaque thoracique et vasculaire, CHRU Brest, France

$16{ }^{4}$ Centre of Cardiovascular and Vascular Surgery, CHU Rennes, France

17 EUniversity of Rennes, Inserm, UMR_1099, France

$18{ }^{6}$ Département de Bactériologie-Virologie, Hygiène et Parasitologie-Mycologie, CHRU Brest, 19 France

$20{ }^{7}$ department of bacteriology, CHU Rennes, France

21 BUniversity of Rennes, Inserm, BRM (Bacterial Regulatory RNAs and Medicine), UMR_1230, 22 France 
${ }^{10}$ Brest University, Inserm, UMR_1078, France

25

26

27 $\Phi 0$

11

12

13

14

15

16

17

28 International telephone: +33299289564

29 Fax number: +33299289464

Corresponding author: Matthieu Revest and Rozenn Le Berre

Email adress: matthieu.revest@chu-rennes.fr, rozenn.leberre@chu-brest.fr,

On behalf of all authors, the corresponding author states that there is no conflict of interest 


\section{Abstract:}

47 Objectives: Prosthetic vascular graft infection (PVGI) is a very severe disease. We aimed to 48 determine the factors associated with treatment failure.

Methods: Patients admitted to two University Hospitals with PVGI were included in this 50 retrospective study. PVGI was classified as possible, probable or proven according to an original set of diagnostic criteria. We defined treatment failure if one of the following events occurred within the first year after PVGI diagnosis: death and infection recurrence due to the 53 same or another pathogen.

Results: 112 patients were diagnosed with possible $(n=26)$, probable $(n=22)$ and proven $(n=64)$ PVGI. Bacterial documentation was obtained for $81 \%$ of patients. The most frequently identified pathogen was Staphylococcus aureus $(n=39)$. Surgery was performed in 96 patients (86\%). Antibiotics were administered for more than 6 weeks in $41 \%$ of patients. Treatment 58 failure occurred in 30 patients $(27.5 \%)$. The factors associated with a lower probability of treatment failure were total removal of the infected graft (OR=0.2, 95\% $\mathrm{Cl}[0.1-0.6])$, rifampicin administration ( $\mathrm{OR}=0.3[0.1-0.9])$ and possible PVGI according to the GRIP criteria $(\mathrm{OR}=0.3$ $61[0.1-0.9])$

Conclusions: Treatment failure occurred in $27.5 \%$ of patients with PVGI. Total removal of the infected graft and rifampicin administration were associated with better outcomes. 
Introduction:

With a frequency estimated from $1 \%$ to $9 \%$ [1-4], prosthetic vascular graft infection (PVGI) is a rare complication of vascular surgery associated with severe consequences: the one-year mortality rate ranges from $19.0 \%$ to $34.4 \%$ [5-8], and limb amputation can exceed $40 \%$ of patients [9]. Despite this heavy clinical burden, many uncertainties still exist regarding the optimal management of this infection. PVGI diagnosis is sometimes hard to ascertain, as no well-defined diagnostic criteria exist. Hence, the conclusions of clinical studies can be biased if rigorous diagnostic criteria are not applied to include real PVGI patients. In addition, the available recommendations on PVGI therapy are only based on small case series and expert opinions [3,10-12]. Medical and surgical treatments should be combined guided by a multidisciplinary team, but little is known about the specific therapeutic modalities to apply. In situ reconstruction with or without graft removal is now thought to be the best surgical option and is the most frequently performed technique $[5,13]$. Proposals on the medical treatment of PVGls have recently been published, highlighting the need of using molecules active against bacteria embedded inside the biofilm, but the authors regret the lack of solid evidence regarding antimicrobial therapy [11].

Thus, our study aimed to determine the occurrence of treatment failure in patients with PVGI in a large bicentric retrospective study by using a systematic diagnostic method. Secondarily, we searched for factors associated with treatment failure in multivariate analysis.

\section{Methods:}

Ethics The Brest and Rennes ethics committees approved this observational study under reference numbers 2018CE.21 and 1585, respectively.

Inclusion All the patients treated for PVGI in the Brest University Hospital, France, between January 2011 and June 2016 or in the Rennes University Hospital, France, between January 
2005 and December 2014 were included in this retrospective cohort study. Patients were identified using the French hospital discharge database. Patients with infection of a biological graft, a coronary graft or stent, a vascular patch, or a vascular endoprosthesis were excluded.

Definition of PVGI PVGI was defined according to the Groupe de Réflexion sur les Infections de Prothèses Vasculaires (GRIP) criteria [14], displayed in Table 1. Patients were classified according to the likelihood of PVGI: possible, probable or proven.

Outcome definition Treatment failure was a composite clinical criterion defined as the occurrence of one of the following events within the first year after PVGI diagnosis: death due to PVGI and infection recurrence due to the same or another pathogen during antimicrobial treatment or after treatment completion. Mortality due to PVGI was assessed by two independent physicians (MP, SP); in the case of disagreement, the opinion of a third physician was sought (RLB or MR). Treatment failure was diagnosed according to the GRIP criteria of PVGI at least 7 days after the initial PVGI diagnosis.

104 Statistical analysis Descriptive data were expressed as medians $\left[25^{\text {th }}-75^{\text {th }}\right.$ percentiles] for into a multivariate logistic regression model. Variable selection was performed using backward and forward selection ( $p \leq 0.05$ ). Adjusted odds ratios were obtained with their $95 \%$ confidence 111 interval [OR $(95 \% \mathrm{Cl})]$. Analysis was performed using R statistical software, version 3.4.4 [15].

Results:

114 Population: 
115 One hundred and twelve patients ( $81.3 \%$ men) were diagnosed with possible, probable and

proven PVGI in 26 (23.2\%), 22 (19.6\%) and 64 cases (57.1\%), respectively. Clinical 117 characteristics and prognosis of patients according to the likelihood of PVGI are displayed in 118 the supplementary table. Forty patients (35.7\%) were treated at the Brest University Hospital, 119 and 72 patients (64.3\%) in Rennes. The median age was 66 [60-75] years (Table 2). The main 120 cardiovascular risk factors were active smoking (84.3\%) and arterial hypertension (60.7\%).

The two main comorbidities were coronary artery disease (42.0\%) and chronic obstructive pulmonary disease (28.6\%).

The site of infection was a peripheral $(n=69)$, an aorto-thoracic $(n=15)$, an aorto-abdominal $(n=24)$ or an axillo-femoral $(n=4)$ graft. Groin incision was performed at the time of graft implantation in 92 cases (81.4\%). Thirty-one patients (27.7\%) needed a second surgery for a postoperative non-infectious complication.

Diagnosis was made after a median time of 51 [16-851] days after graft implantation. At the time of diagnosis, all patients but three (97.3\%) presented with a clinical sign, mainly pain (65.9\%) and fever (62.0\%). The C-reactive protein level was $>10 \mathrm{mg} / \mathrm{L}$ for $92.3 \%$ of patients. Leucocytes were $>10 \mathrm{G} / \mathrm{L}$ for $67.1 \%$ of patients. A CT scan was performed in 58 patients (51.8\%) and contributed to the diagnosis in $89.7 \%$ of cases, whereas Doppler was performed in 15 patients (13.4\%) and contributed to diagnosis in $80.0 \%$ of cases. Patients with aortic PVGI presented more frequently with fever than patients with peripheral PVGI $(78.6 \%$ vs $51.5 \%, p<0.01)$ and less frequently with local erythema (34.3\% vs $65.0 \%, p<0.01)$.

Infections were microbiologically documented in 91 patients (81.3\%), including 37 patients with polymicrobial infection (40.7\%). Among patients undergoing surgery with intraoperative bacterial sampling ( $n=92), 71(77.2 \%)$ had a positive bacterial culture. Blood culture was performed in 53 patients (47.3\%), and 33 (62.3\%) cultures yielded a positive result. One infection due to Coxiella burnetti was documented with positive serology. The most frequent pathogens are displayed in Table 3 and were gram-positive cocci $(62.5 \%)$, including 
Staphylococcus aureus (27.3\%) and Enterococcus sp. (14.6\%); gram-negative bacilli (26.4\%); and anaerobes (7.7\%). The anatomical site of the PVGI did not influence the spectrum of infecting agents and patients with polymicrobial infections did not suffer more frequently from postoperative wound healing disorders than patients with monomicrobial infections.

\section{Treatment:}

147 All patients received antimicrobial therapy. Empirical treatment was given to 76 patients 148 (67.9\%), usually a beta-lactam, with an adjunct of an anti-MRSA agent in 46 patients (60.5\%).

149 Twenty-seven patients received antibacterial therapy before intraoperative bacterial sampling 150 for a median duration of 6 [3-14] days. Receiving more than 7 days of antimicrobial treatment 151 before surgery was associated with negative bacterial culture of intraoperative sampling $152(\mathrm{OR}=2.44, \mathrm{p}=0.02)$. This effect was not observed for shorter preoperative treatment durations. 153 The remaining 36 patients were given culture-guided antibiotic therapy directly.

154 A rifampicin combination was used for definite therapy in 31 patients (27.7\%), among whom 15521 were infected with $S$. aureus, 7 with coagulase negative staphylococci, 1 with 156 Mycobacterium bovis and 2 with a non-documented infection. The median treatment duration 157 was 6 [6-9] weeks. Antibiotics were administered for at least 4 weeks in 84 patients (82.6\%). 158 Forty patients (40.8\%) received antibiotic therapy for more than 6 weeks, including 8 patients (7.1\%) receiving suppressive lifelong antimicrobial therapy.

160 Surgical treatment was performed in 96 patients (85.7\%). Thirty-eight (33.9\%) and ten patients $161(8.9 \%)$ required a second and a third surgery, respectively. The median time between the 162 diagnosis of PVGI and the first surgery was 1 [0-6] day. Microbiological optimal surgery (i.e., 163 total removal of the infected prosthesis) was performed in 48 patients (42.9\%). Reconstruction 164 was needed in 60 patients and was performed with an allograft in 20 cases (20/60, 33.3\%), an 165 autologous vein in 22 cases $(22 / 60,36.7 \%)$ and prosthetic material in the remaining 18 patients. Five patients were treated initially with an endoprosthesis; two of those patients 
167 required another surgery for total replacement with an allograft. Limb amputation was 168 performed in 18 cases (16.8\%).

169 The factors associated with optimal surgery in univariate analysis were peripheral-arterial 170 PVGI vs abdomino-thoracic PVGI (47.9\% vs 16.7\%, $\mathrm{p}=0.02)$, age (63 vs 66 years old, $\mathrm{p}<0.01$ ), 171 and year of diagnosis $(p=0.01)$. Patients diagnosed with PVGI after 2013 were more likely to 172 undergo the optimal surgery than patients diagnosed in 2013 or before $(56.4 \%$ vs $35.6 \%$, $173 \mathrm{p}=0.04)$. All-cause mortality did not differ significantly between patients with microbiological 174 optimal and microbiological non-optimal surgery.

176 Outcome:

177 All patients but one were followed for more than one year. Three patients $(2.7 \%)$ and 25 patients $(22.3 \%)$ died during the first 30 days and the first year after PVGI diagnosis, respectively. There were no intraoperative deaths.

180 Treatment failure occurred in 30 patients (27.5\%) at one year of follow-up. Death due to PVGI 181 occurred in 12 patients (10.7\%), including 3 patients with infection recurrence. Twenty-two 182 patients (19.6\%) presented with infection recurrence that occurred before treatment 183 completion in 13 cases. For 6 patients (5.4\%), infection recurrence was due to another 184 microorganism and for 15 patients (13.4\%) to the same pathogen. The remaining patient 185 successively presented with these two events. The all-cause mortality rate at one year was 186 higher in patients with treatment failure $(53.3 \%$ vs $10.1 \%, p<0.01)$.

187 According to univariate analysis, the factors significantly associated with a lower risk of 188 treatment failure were microbiological optimal surgery (Figure), rifampicin administration and 189 PVGI diagnostic probability as possible vs certain or probable according to the GRIP criteria 190 (Table 4). No microbiological data were associated with treatment failure. 
All three factors remained independently associated with a lower risk of treatment failure in the multivariate analysis: microbiological optimal surgery ( $O R=0.22[0.07-0.57], p<0.01)$, possible PVGI according to the GRIP criteria compared to probable and proven PVGI (OR=0.27 [0.070.85], $\mathrm{p}=0.04$ ), and rifampicin administration ( $\mathrm{OR}=0.30$ [0.09-0.87], $\mathrm{p}=0.04$ ). As the diagnosis of PVGI for the patients classified in the "possible" group could be uncertain, we performed another multivariate analysis including only the patients with probable or proven PVGl: microbiological optimal surgery and rifampicin administration remained significantly associated with a better outcome.

\section{Discussion:}

201 Important information comes from this large bicentric retrospective study: i) treatment failure 202 occurred in $27.5 \%$ of 112 patients and was associated with a high mortality rate of $53.3 \%$ at one year; ii) use of a rifampicin-combined regimen was associated with a better outcome; and iii) removal of the entire infected material also.

The lack of clear validated diagnostic criteria to define PVGI represents one of the most problematic issues for improving patient management and literature analysis. In a pioneering study published in 2005, Fitzgerald et al argued for a provisional set of diagnostic criteria, such as the Duke criteria used for infective endocarditis [12], and an English group of investigators also recently advocated for this [16]. However, to the best of our knowledge, no study on PVGI using this kind of diagnostic method has been published so far, and the results of previous studies can therefore be questioned. We based our work on the diagnostic criteria proposed by a French multidisciplinary expert group (GRIP) [14] to improve the diagnostic accuracy. We included all the patients considered to have a PVGI by their treating physicians and then, we classified all the patients according to the GRIP criteria. PVGI diagnosis likelihood is very high for patients classified as probable and proven PVGI, but quite low for patients with possible PVGI. Besides, treatment failure occurred more frequently in patients diagnosed with proven 
and probable PVGI than in patients with possible PVGI. Our study reflects the real life: due to

218 the severity of the disease, some patients are treated for PVGI even if the diagnosis is not confirmed. However, our results corroborate the GRIP classification according to diagnostic probability, and we hope that this systematic method could help physicians to manage this hard-to-treat infection.

We confirmed that PVGI is a very severe infection, with more than $27 \%$ of patients with treatment failure and an all-cause mortality rate of $22 \%$ at one year. Our treatment failure rate is similar to that of previous reports $[5,17,18]$. PVGI management relies on a multidisciplinary approach and requires antibiotic therapy associated with surgical procedures. The best antimicrobial agents and duration of antibiotic therapy for PVGI remain unknown. Most of our patients were initially treated with a high dosage of intravenous beta-lactam agents as recommended [11]. It was impossible to capture the impact of the different initial therapeutic options; surgical procedures probably had an initial greater impact than antibiotic treatment, but we found that the use of rifampicin was associated with a better outcome. This has already been demonstrated for joint-prosthesis infection [19] and for PVGI [5,17]. Rifampicin offers many advantages in difficult-to-treat infections: high biodisponibility, a large diffusion capacity, a large spectrum on gram-positive cocci, intense bactericidal activity even on intracellular bacteria [20], and on bacteria with altered metabolic state inside the biofilm [21,22]. In our work, the rifampicin effect was not differentiated according to the causative pathogen because of the small sample size. However, rifampicin was essentially used for S. aureus PVGI, and our results add another building block for its importance in material-related $S$. aureus infections.

One other question regarding the treatment of PVGI refers to the duration of antibiotic therapy. Available data only come from non-comparative studies whose objectives were not the evaluation of treatment duration. Most of those publications report 6 or 12 weeks of treatment, but others report shorter or longer antibiotic therapy. In our study, most patients received antibiotics for 6 weeks, regardless of whether the surgical treatment was optimal. The survival 
and treatment failure rates were similar to those of other cohorts, and we did not find any impact of treatment duration on treatment failure. Thus, 6-week-long treatment seem to be long enough for PVGI.

247 A negative effect of more than 7 days of preoperative antimicrobial therapy was found on the 248 bacterial growth of intraoperative samples. This effect was not observed for shorter treatments 249 but could be different according to the pathogens and antimicrobial drugs. To minimize the risk 250 of perioperative sample culture negativity, preoperative antibiotic therapy should be reserved 251 for patients with sepsis.

252 Several techniques have been proposed for the surgical treatment of PVGI. Similar to osteo253 articular infection, total removal of the entire infected graft is encouraged $[3,23]$. This statement 254 is supported by little proof [7,24], and some studies have not found this positive impact [5], 255 sometimes even demonstrating a negative effect [25]. Our study supports the need for this 256 microbiological optimal surgical treatment in multivariate analysis. However, complete graft 257 excision is not always possible or can be associated with poor functional results. The choice 258 of surgical treatment may be guided by the operability of the patient and therefore may be 259 correlated with the risk of mortality and induced morbidity. In our study, $85.7 \%$ of patients underwent surgery, and $42.9 \%$ of patients underwent microbiological optimal surgery with total removal of the infected vascular prosthesis. Most recent studies reported complete excision of the infected prosthetic vascular graft in $22.9 \%$ to $85.5 \%$ of cases $[5-7,18]$. In our study, microbiological optimal surgery was more frequently performed in young patients with peripheral-arterial surgery but did not depend on one specific comorbidity. The surgical rates increased every year. One explanation for this increasing rate is the recent improvements in surgical techniques and in anaesthesiology. Performing optimal surgery is now an option in patients who would have been previously recused. Second, in both participating centres, a multidisciplinary team that included infectious disease clinicians, surgeons and bacteriologists was established during the study period. 
There were several limitations in this study. First, this was a retrospective study with all the associated limitations. However, we used a recognized definition of PVGI using criteria systematically recorded when taking care of patients with PVGI. Thus, we only included patients with a high probability of PVGI. In addition, missing data were very rare, and we were able to collect one-year follow-up data for all the patients except one. Moreover, due to the scarcity of the disease and the vast heterogeneity of patients, it is very difficult to conduct prospective multicentre studies in this field. Retrospective cohort studies such as ours are probably the least incorrect option to improve our knowledge about this very severe disease. Second, this study included patients with various surgical and medical approaches, but this reflects the vast heterogeneity of PVGI patient management. We aimed to describe the classic care of patients with PVGI in real life to draw interesting conclusions in daily practice.

\section{Conclusion:}

283 In conclusion, PVGI, a biofilm-associated infection, is associated with a high risk of treatment 284 failure. In this retrospective study, complete excision of the infected graft and rifampicin 285 administration were associated with favourable outcomes. As complete excision of the graft 286 constitutes a major surgery, PVGI diagnosis should be based on a recognized definition. Our 287 study demonstrated the reliability of the GRIP criteria for diagnosis. Prospective studies using 288 such a definition of PVGI are needed to clarify the best PVGI management choices. 
Bibliography:

291 1. O'Connor S, Andrew P, Batt M, Becquemin JP. A systematic review and meta-analysis of 292 treatments for aortic graft infection. J Vasc Surg. 2006;44:38-45.e8.

293 2. Seeger JM. Management of patients with prosthetic vascular graft infection. Am Surg. 294 2000;66:166-77.

295 3. Darouiche RO. Treatment of Infections Associated with Surgical Implants. N Engl J Med. 296 2004;350:1422-9.

4. Anagnostopoulos A, Ledergerber B, Kuster SP, Scherrer AU, Näf B, Greiner MA, et al. Inadequate Perioperative Prophylaxis and Postsurgical Complications After Graft Implantation Are Important Risk Factors for Subsequent Vascular Graft Infections: Prospective Results From the Vascular Graft Infection Cohort Study. Clin Infect Dis. 2019;69:621-30.

5. Erb S, Sidler JA, Elzi L, Gurke L, Battegay M, Widmer AF, et al. Surgical and antimicrobial treatment of prosthetic vascular graft infections at different surgical sites: a retrospective study of treatment outcomes. PloS One. 2014;9:e112947.

6. Elens M, Dusoruth M, Astarci P, Mastrobuoni S, Bosiers MJ, Nardella J, et al. Management and Outcome of Prosthetic Vascular Graft Infections: A Single Center Experience. Vasc Endovascular Surg. 2018;1538574418754453.

7. Saleem BR, Meerwaldt R, Tielliu IFJ, Verhoeven ELG, Dungen JJAM van den, Zeebregts CJ. Conservative treatment of vascular prosthetic graft infection is associated with high mortality. Am J Surg. 2010;200:47-52.

8. Chiesa R, Astore D, Frigerio S, Garriboli L, Piccolo G, Castellano R, et al. Vascular prosthetic graft infection: epidemiology, bacteriology, pathogenesis and treatment. Acta Chir Belg. 2002;102:238-47.

9. O'Hara PJ, Hertzer NR, Beven EG, Krajewski LP. Surgical management of infected abdominal aortic grafts: review of a 25-year experience. J Vasc Surg. 1986;3:725-31.

10. Leroy O, Meybeck A, Sarraz-Bournet B, d'Elia P, Legout L. Vascular graft infections. Curr Opin Infect Dis. 2012;25:154-8.

11. Revest M, Camou F, Senneville E, Caillon J, Laurent F, Calvet B, et al. Medical treatment of prosthetic vascular graft infections: Review of the literature and proposals of a Working Group. Int J Antimicrob Agents. 2015;46:254-65.

12. FitzGerald SF, Kelly C, Humphreys H. Diagnosis and treatment of prosthetic aortic graft infections: confusion and inconsistency in the absence of evidence or consensus. J Antimicrob Chemother. 2005;56:996-9.

13. Batt M, Feugier P, Camou F, Coffy A, Senneville E, Caillon J, et al. A Meta-Analysis of Outcomes After In Situ Reconstructions for Aortic Graft Infection. Angiology. 2017;3319717710114.

14. Senneville E. Diagnostic des infections sur prothèses vasculaires [Internet]. ClermontFerrand; 2013 [cited 2019 Jan 27]. Available from: http://www.infectiologie.com/UserFiles/File/medias/JNI/JNI13/2013-JNI-Diag-IPVsenneville.pdf 
15. R Core Team. R: A Language and Environment for Statistical Computing [Internet]. Vienna, Austria: R Foundation for Statistical Computing; 2018. Available from: https://www.Rproject.org/

16. Lyons OTA, Baguneid M, Barwick TD, Bell RE, Foster N, Homer-Vanniasinkam S, et al. Diagnosis of Aortic Graft Infection: A Case Definition by the Management of Aortic Graft Infection Collaboration (MAGIC). Eur J Vasc Endovasc Surg Off $\mathrm{J}$ Eur Soc Vasc Surg. 2016;52:758-63.

17. Legout L, Delia P, Sarraz-Bournet B, Rouyer C, Massongo M, Valette M, et al. Factors predictive of treatment failure in staphylococcal prosthetic vascular graft infections: a prospective observational cohort study: impact of rifampin. BMC Infect Dis. 2014;14:228.

18. Legout L, Sarraz-Bournet B, D'Elia PV, Devos P, Pasquet A, Caillaux M, et al. Characteristics and prognosis in patients with prosthetic vascular graft infection: a prospective observational cohort study. Clin Microbiol Infect Off Publ Eur Soc Clin Microbiol Infect Dis. 2012;18:352-8.

19. Senneville E, Joulie D, Legout L, Valette M, Dezèque H, Beltrand E, et al. Outcome and predictors of treatment failure in total hip/knee prosthetic joint infections due to Staphylococcus aureus. Clin Infect Dis Off Publ Infect Dis Soc Am. 2011;53:334-40.

20. Boudjemaa R, Steenkeste K, Jacqueline C, Briandet R, Caillon J, Boutoille D, et al. Live intramacrophagic Staphylococcus aureus as a potential cause of antibiotic therapy failure: observations in an in vivo mouse model of prosthetic vascular material infections. J Antimicrob Chemother. 2018;73:2418-21.

21. Zheng Z, Stewart PS. Penetration of Rifampin through Staphylococcus epidermidis Biofilms. Antimicrob Agents Chemother. 2002;46:900-3.

22. Boudjemaa R, Briandet R, Revest M, Jacqueline C, Caillon J, Fontaine-Aupart M-P, et al. New Insight into Daptomycin Bioavailability and Localization in Staphylococcus aureus Biofilms by Dynamic Fluorescence Imaging. Antimicrob Agents Chemother. 2016;60:4983-90.

23. Legout L, D'Elia PV, Sarraz-Bournet B, Haulon S, Meybeck A, Senneville E, et al. Diagnosis and management of prosthetic vascular graft infections. Med Mal Infect. 2012;42:102-9.

24. Maze MJ, Laws P, Buckenham T, Pithie A, Gallagher K, Metcalf $S$, et al. Outcomes of infected abdominal aortic grafts managed with antimicrobial therapy and graft retention in an unselected cohort. Eur J Vasc Endovasc Surg Off J Eur Soc Vasc Surg. 2013;45:373-80.

25. Calligaro KD, Veith FJ, Schwartz ML, Goldsmith J, Savarese RP, Dougherty MJ, et al. Selective preservation of infected prosthetic arterial grafts. Analysis of a 20 -year experience with 120 extracavitary-infected grafts. Ann Surg. 1994;220:461-71. 
Figure 1. Survival probability without treatment failure

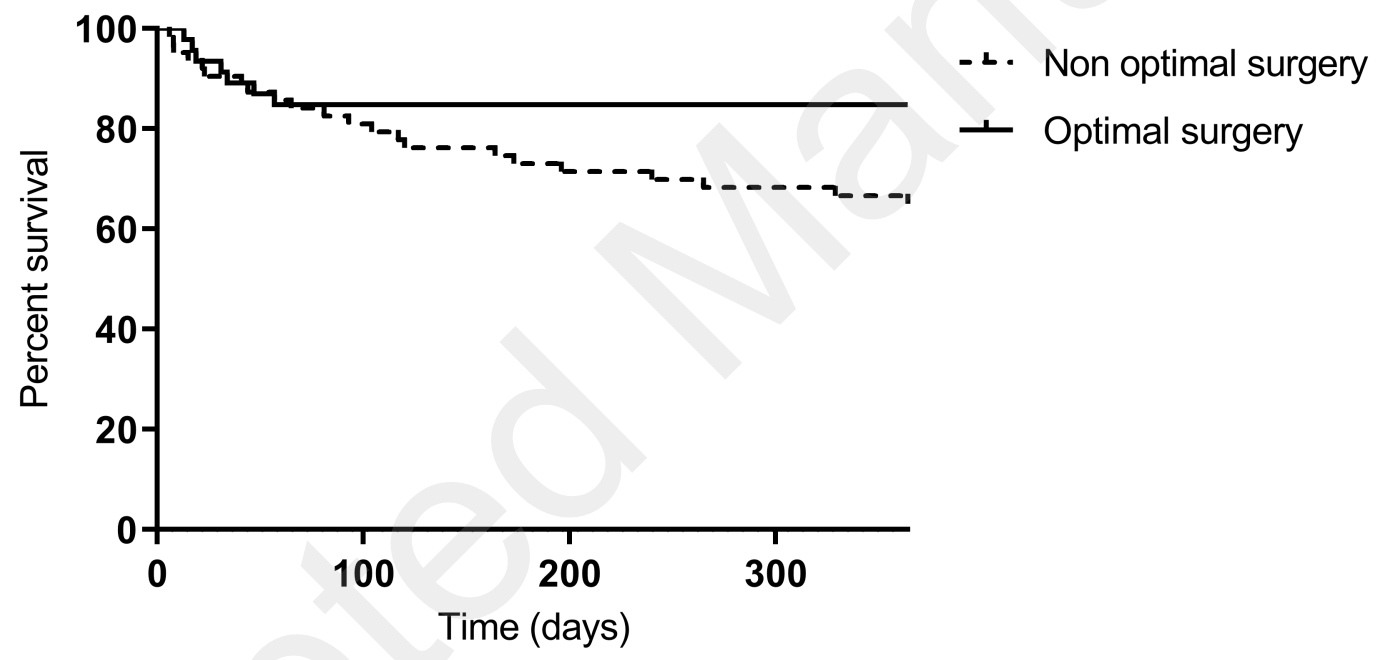


Tables:

Table 1. Groupe de Réflexion sur les Infections de Prothèses Vasculaires (GRIP) diagnostic criteria

Proven PVGI:

Two criteria among the following are required:

- positive smear or culture of intra-operative samples of the vascular prosthesis or periprosthetic tissues

- periprosthetic suppuration

- presence of collections or periprosthetic air bubbles after eight postoperative weeks

- vascular prosthesis exposition through wound or gut

Probable PVGI:

Two clinical criteria among the following are required:

- fever, shaking chills, septic shock, or haemorrhagic shock due to aorto-digestive fistula or anastomotic rupture of the bypass

- local pain

- erythema

- local tumefaction

- suppurative fistula

- abscess or lack of vascular material integration (except PTFE implant)

And a microbiological criterion:

- one positive blood culture

- if commensal flora bacteria are isolated, two positive haemocultures are required

Or a radiological criterion:

- presence or persistence of collection and/or periprosthetic air bubbles after 8 postoperative weeks

- abscess

- false aneurysm

Possible PVGI:

One criterion among the following is required

- a clinical criterion (as listed above)

- a biological criterion: C-reactive protein level more than $10 \mathrm{mg} / \mathrm{L}$ and/or hyperleukocytosis more than $10 \mathrm{~g} / \mathrm{L}$

- a radiological criterion (as listed above) 
Table 2. Population characteristics

\begin{tabular}{|c|c|c|c|}
\hline Characteristics & $\begin{array}{l}\text { Treatment success } \\
(n=82)\end{array}$ & $\begin{array}{c}\text { Treatment } \\
\text { failure }(n=30)\end{array}$ & Total $(n=112)$ \\
\hline Men, $n(\%)$ & 68 (82.9) & $23(77.7)$ & $91(81.3)$ \\
\hline Age (years), median [IQ1-IQ2) & $65[59-73]$ & $67[61-78]$ & $66[60-75]$ \\
\hline Diabetes mellitus, $n$ (\%) & $18(22.0)$ & $10(33.3)$ & $28(25.0)$ \\
\hline $\begin{array}{l}\text { Chronic obstructive pulmonary disease, } n \\
\text { (\%) }\end{array}$ & $23(28.1)$ & $9(30.0)$ & $32(28.6)$ \\
\hline Arterial hypertension, $n$ (\%) & $49(60.5)$ & $19(63.3)$ & $68(60.7)$ \\
\hline Coronary artery disease, $n(\%)$ & $33(40.2)$ & $14(47.7)$ & $47(42.0)$ \\
\hline Solid cancer, $n(\%)$ & $20(24.4)$ & $5(17.7)$ & $25(22.3)$ \\
\hline Stroke, $n(\%)$ & $13(15.9)$ & $2(6.7)$ & $15(13.4)$ \\
\hline Severe renal insufficiency, $n(\%)$ & $15(18.3)$ & $7(24.1)$ & $22(19.6)$ \\
\hline Immunosuppression, $n(\%)$ & $10(12.2)$ & $5(16.7)$ & $15(13.4)$ \\
\hline Active smoking, $n(\%)$ & $56(86.2)$ & $19(79)$ & $75(84.3)$ \\
\hline \multicolumn{4}{|l|}{ Presentation at time of diagnosis } \\
\hline Fever, $n(\%)$ & $50 / 79(63.3)$ & $17 / 29(58.6)$ & $67 / 108(62.1)$ \\
\hline Local pain, $n$ (\%) & $41 / 60(68.3)$ & $13 / 24(59.1)$ & $54 / 82(65.9)$ \\
\hline Local erythema, $n(\%)$ & $37 / 70(52.9)$ & $14 / 25(56.0)$ & $51 / 95(53.7)$ \\
\hline Fistula or swelling, $n$ (\%) & $40 / 76(52.6)$ & $17 / 28(60.7)$ & $57 / 104(54.8)$ \\
\hline Scar disunion, $\mathrm{n}(\%)$ & $35 / 76(46.1)$ & $9 / 25(36.0)$ & 44/101 (43.6) \\
\hline White blood count $>10 \mathrm{G} / \mathrm{L}, n$ (\%) & $47 / 73(64.4)$ & $18 / 24(75.0)$ & $65 / 97(67.0)$ \\
\hline C-reactive protein $>10 \mathrm{mg} / \mathrm{L}, n(\%)$ & $38 / 42(90.5)$ & $15 / 15(100)$ & $53 / 59(93.0)$ \\
\hline
\end{tabular}


Table 3. Microbiological data

$\begin{array}{lc}\text { Bacterial documentation per } & \text { N (\%) } \\ \text { patient Bacterial documentation } & 91 / 112 \\ \text { Polymicrobial PVGI } & (81.3) \\ \text { Positive preoperative samples } & 37 / 112 \\ \text { Positive blood samples } & (33.0) 71 / 96 \\ & \\ \text { Microorganisms isolated } & 144(100) \\ \text { (n=144) Aerobic Gram-positive } & 90(62.5) \\ \text { Methicillin-sensitive Staphylococcus } & 36(25.0) \\ \text { aureus Methicillin-resistant } & 3(2.1) \\ \text { Staphylococcus aureus Coagulase- } & 17(11.8) \\ \text { negative staphylococci Enterococcus sp. } & 21(14.6) \\ \text { Streptococcus sp. } & 13(9.0) \\ \text { Aerobic Gram-negative bacilli } & 38(26.4) \\ \quad \text { Escherichia coli } & 12(8.3) \\ \text { Pseudomonas } & 7(4.9) \\ \text { aeruginosa Various } & 19(13.2) \\ \text { Anaerobes } & 11(7.7) \\ \text { Candida } & 1(0.7) \\ \text { sp. Others } & 4(2.8)\end{array}$

Table 4. Factors associated with poor outcome in univariate and multivariate analyses

OR $[95 \% \mathrm{Cl}] \quad \mathrm{p}$-value $\quad$ OR $[95 \% \mathrm{Cl}] \quad \mathrm{p}$-value

Optimal surgery

$0.018 \quad 0.22[0.07-0.57]$

$p<0.01$

Rifampicin administration Diagnostic

[0.10-0.87] 0.41

$0.10 .30[0.09-0.87]$

0.04

[0.11-1.27] 0.40

0.13

0.27 [0.07-0.85]

0.04 
Supplementary table. Population characteristics according to GRIP definition of PVGI

\begin{tabular}{|c|c|c|c|c|}
\hline Characteristics & Total $(n=112)$ & $\begin{array}{l}\text { Proven or probable } \\
\text { PVGI }(n=86)\end{array}$ & $\begin{array}{c}\text { Possible } \\
\text { PVGI }(n=26)\end{array}$ & P-value \\
\hline Men, $n(\%)$ & $91(81.3)$ & $73(84.9)$ & $18(69.2)$ & NS \\
\hline Age (years), median [IQ1-IQ2] & $66[60-75]$ & $66[60-75]$ & $61[59-73]$ & $<0.05$ \\
\hline Diabetes mellitus, $n(\%)$ & $28(25.0)$ & $24(27.9)$ & $4(15.4)$ & NS \\
\hline $\begin{array}{l}\text { Chronic obstructive pulmonary disease, } \\
n(\%)\end{array}$ & $32(28.6)$ & $23(26.7)$ & $9(34.6)$ & NS \\
\hline Arterial hypertension, $n$ (\%) & $68(60.7)$ & $51(60.0)$ & $17(65.4)$ & NS \\
\hline Coronary artery disease, $n$ (\%) & $47(42.0)$ & $38(44.2)$ & $9(34.6)$ & NS \\
\hline Solid cancer, $n$ (\%) & $25(22.3)$ & $19(22.1)$ & $6(23.1)$ & NS \\
\hline Stroke, $n(\%)$ & $15(13.4)$ & $14(16.3)$ & $1(3.8)$ & NS \\
\hline Severe renal insufficiency, $n(\%)$ & $22(19.6)$ & $17(20.0)$ & $5(19.2)$ & NS \\
\hline Immunosuppression, $n$ (\%) & $15(13.4)$ & $12(14.0)$ & $3(11.5)$ & NS \\
\hline Active smoking, $n$ (\%) & $75(84.3)$ & $59(83.1)$ & $16(88.9)$ & NS \\
\hline \multicolumn{5}{|l|}{ Initial surgery } \\
\hline Peripheral PVGI, n (\%) & $69(61.6)$ & $54(62.8)$ & $15(57.7)$ & NS \\
\hline Groin incision & $92(81.4)$ & $70(82.6)$ & $21(80.8)$ & NS \\
\hline \multicolumn{5}{|l|}{ Presentation at time of diagnosis } \\
\hline Fever, $n(\%)$ & $67 / 108(62.1)$ & $54(65.1)$ & $13(52.0)$ & NS \\
\hline Local pain, $n$ (\%) & $54 / 82(65.9)$ & $44(65.7)$ & $10(66.7)$ & NS \\
\hline Local erythema, $n$ (\%) & $51 / 95(53.7)$ & $40(54.1)$ & $11(52.4)$ & NS \\
\hline Fistula or swelling, $n$ (\%) & $57 / 104(54.8)$ & $47(58.0)$ & $10(43.5)$ & NS \\
\hline Scar disunion, $\mathrm{n}(\%)$ & $44 / 101(43.6)$ & $33(42.3)$ & $11(47.8)$ & NS \\
\hline White blood count $>10 \mathrm{G} / \mathrm{L}, n$ (\%) & $65 / 97(67.0)$ & $51(68.0)$ & $14(63.6)$ & NS \\
\hline C-reactive protein $>10 \mathrm{mg} / \mathrm{L}, n(\%)$ & $53 / 59(93.0)$ & $41(93.2)$ & $12(92.3)$ & NS \\
\hline Microbiological documentation, $n(\%)$ & $91(81.3)$ & $78(90.7)$ & $13(50)$ & $<0.05$ \\
\hline Polymicrobial infection, $n$ (\%) & $37(33.0)$ & $30(34.9)$ & $7(26.9)$ & NS \\
\hline \multicolumn{5}{|l|}{ Treatment and outcome } \\
\hline Rifampicin-based regimen, $n(\%)$ & $31(27.7)$ & $25(29.1)$ & $6(23.1)$ & NS \\
\hline $\begin{array}{l}\text { Antimicrobial therapy for } 6 \text { weeks or } \\
\text { more, } n(\%)\end{array}$ & $40(40.8)$ & $32(41.6)$ & $8(38.1)$ & NS \\
\hline Optimal surgery, $n(\%)$ & $48(42.9)$ & $41(47.7)$ & $7(26.9)$ & NS \\
\hline Death at one year, $n(\%)$ & $25(22.3)$ & $20(23.5)$ & 5 (19.2) & NS \\
\hline Treatment failure, $n(\%)$ & $30(27.5)$ & $26(31.3)$ & $4(15.4)$ & NS \\
\hline
\end{tabular}


Electronic Supplementary Material

\section{Click here to access/download \\ Electronic Supplementary Material Supplementary table.docx}

